\title{
AN OVERVIEW OF GUILLAIN BARRE SYNDROME WITH REFERENCE TO CLINICAL FEATURES AND PROGNOSTIC OUTCOME IN PATIENTS ATTENDING A TERTIARY CARE HOSPITAL
}

\author{
N. A. V. S. K. Ravi Kumar1, Kanduri Soumya ${ }^{2}$
}

${ }_{1}^{1}$ Associate Professor, Department of General Medicine, Andhra Medical College, Visakhapatnam, Andhra Pradesh, India.

2Postgraduate Student, Department of General Medicine, Andhra Medical College, Visakhapatnam, Andhra Pradesh, India.

ABSTRACT
BACKGROUND
Guillain Barre Syndrome (GBS) is the most common cause of acute or subacute generalized paralysis in practice. Proper
understanding of pathology, clinical presentation, appropriate investigations and interventions when needed may save these
patients from mortality and severe morbidity. King George Hospital located in Visakhapatnam predominantly covers most of the
population of North Coastal Andhra Pradesh, Odisha. It offers medical management to people of different age groups, races and
different socio-economic status. Hence it is ideal to conduct a study in this institution.
Aims and Objectives- To evaluate the clinical features and assess the prognostic outcome in patients with Guillain Barre Syndrome.

\section{MATERIALS AND METHODS}

After taking prior consent, 40 patients of Guillain Barre Syndrome were studied from January 2016 to January 2017. Their clinical features, electrodiagnosis, treatment outcomes and prognosis were assessed.

\section{RESULTS}

18 patients had AIDP, 16 had AMAN, 12 had AMSAN, and 2 presented with the Miller Fischer variant. 38 patients received Intravenous Immunoglobulin (IVIG). 2 of them were given only Methyl Prednisolone. 5 patients went into respiratory failure despite being given IVIG and had to be given ventilator support. Patients with AIDP and AMAN showed recovery from Grade 5 to Grade 2. 2 patients with AMSAN variant had residual disability at the time of discharge. 12 patients had autonomic disturbance but recovered fully. There was no mortality among the study subjects during the period of study.

\section{CONCLUSION}

We can conclude from our study that Guillain Barre Syndrome is a treatable neurological condition with varying patterns of recovery. Intravenous immunoglobulin forms the mainstay of pharmacological treatment with recovery being shown in invariably all the patients who have received IVIG.

\section{KEY WORDS}

Guillain Barre Syndrome, Clinical Features, Prognosis.

HOW TO CITE THIS ARTICLE: Kumar NAVSKR, Soumya K. An overview of Guillain Barre syndrome with reference to clinical features and prognostic outcome in patients attending a tertiary care hospital. J. Evolution Med. Dent. Sci. 2019;8(01):1-4, DOI: $10.14260 /$ jemds/2019/1

\section{BACKGROUND}

Guillain Barre Syndrome (GBS) is the most common cause of acute or subacute generalized paralysis in practice. It occurs in all parts of the world and in all seasons. It affects children and adults of all ages and both sexes. ${ }^{1}$ The severity of Guillain-Barré Syndrome varies from mild weakness to total paralysis and respiratory failure, sometimes leading to death.

Proper understanding of pathology, clinical presentation, appropriate investigations and interventions when needed may save these patients from mortality and severe morbidity. Majority of patients recover with mild motor deficits or sensory complaints in the feet or legs. In approximately 10 percent, however, the residual disability is pronounced.

'Financial or Other Competing Interest': None.

Submission 27-11-2018, Peer Review 22-12-2018,

Acceptance 29-12-2018, Published 07-01-2019.

Corresponding Author:

Dr. Soumya Kanduri,

Flat No. 402, 39-22-11/2,

Sri Durga Residency, Kalinganagar,

Madhavadhara, Visakhapatnam-530007,

Andhra Pradesh, India.

E-mail: ksoumya1991@gmail.com

DOI: $10.14260 /$ jemds $/ 2019 / 1$
Approximately 3 to 5 percent of patients do not survive the illness, even in the best equipped hospitals. Some 5 to 10 percent of patients encounter one or more recurrences of the acute polyneuropathy.

King George Hospital located in Visakhapatnam predominantly covers most of the population of North Coastal Andhra Pradesh, Odisha. It offers medical management to people of different age groups, races and different socio- economic status. Hence it is ideal to conduct a study in this institution.

\section{Aims and Objectives of the Study-}

1. To evaluate the antecedent events of Guillain-Barré Syndrome in patients attending King George Hospital.

2. To find out the incidence of Guillain-Barré Syndrome at our hospital.

3. To assess the temporal profile of illness and its clinical features.

4. To measure the severity of illness with reference to electrodiagnostic studies.

5. To assess the prognostic outcome with electrodiagnostic studies and treatment modalities. 


\section{MATERIALS AND METHODS}

\section{Inclusion Criteria}

1. Patients admitted with features suggestive of flaccid progressive symmetrical weakness affecting two or more limbs with reduced or absent deep tendon reflexes.

2. Patients admitted with progression of weakness of less than 4 weeks duration.

\section{Exclusion Criteria}

1. Patients with features of hypokalaemic periodic paralysis.

2. Patients with features of upper motor neuron signs and symptoms.

3. Patients admitted with history of tick bite preceding the illness.

4. Patients admitted with history of exposure to toxins like organophosphates.

\section{Number of Cases Studied}

40

\section{Study Design}

Descriptive study.

\section{Duration of Study}

January 2016 - January 2017.

Detailed neurological examination including higher mental functions, cranial nerves, motor system, sensory system and autonomic system was done for all the patients. Motor power in these patients were assessed according to Medical Research Council grading.

Autonomic dysfunction was looked for in all these patients. History of Dryness of mouth, postural giddiness and defective sweating over the body were specifically asked for.

Blood pressure was routinely taken in lying and sitting posture and if possible in standing posture to bring out orthostatic hypotension. Respiratory function was assessed at bedside using breath-holding time, single breath count, chest expansion, Litten's phenomenon.

Basic investigations like complete blood count, peripheral smear, blood sugar and urea, serum creatinine and electrolytes, erythrocyte sedimentation rate, daily electrocardiogram, chest x-ray were done for all the patients.

Lumbar puncture was done for all patients and Cerebro Spinal Fluid was sent for Gram's stain, biochemical and cytological analysis. Electrophysiological studies were conducted at EMG Laboratory, KGH, Visakhapatnam.

Nerve conduction studies were done in both upper and lower limbs. Conduction velocities, Compound Muscle Action Potentials, F-waves and H-reflex were studied. Magnetic Resonance Imaging of whole spine was done in all the patients.

\section{RESULTS}

All the 40 patients were above the age of 15; among which 11 $(27.5 \%)$ patients were below the age of 30,25 patients (62.5\%) were between 30-60 years, 4 patients $(10 \%)$ were above the age of 60 . In the 40 patients studied, 23 were male and 17 were female.
Among the 40 patients, 36 patients had weakness of both upper and lower limbs. 6 patients had neck muscle weakness. 4 patients had features suggestive of bulbar weakness. 3 patients had ocular muscle involvement. 13 patients gave history suggestive of sensory disturbance and 12 patients had electrophysiological evidence of sensory involvement. 3 patients had bilateral lower motor neuron type of facial weakness. 4 patients developed altered sensorium for a short period with complete recovery within days.

Among these 40 patients, 12 patients developed respiratory distress and 5 of them required ventilator for life support. Patients were weaned from ventilator with favourable outcome. 12 patients presented with some form of autonomic dysfunction. Orthostatic hypotension was found in 3 patients. Cardiac arrhythmias in electrocardiogram including ventricular, atrial ectopics, sinus tachycardia and ST-T changes were noted in 5 patients.

\begin{tabular}{|c|c|c|}
\hline Presentation & Number of Patients & Percentage \\
\hline Quadriparesis & 36 & $90 \%$ \\
\hline Paraplegia & 2 & $5 \%$ \\
\hline Respiratory Distress & 12 & $30 \%$ \\
\hline B/L Facial Palsy & 3 & $7.5 \%$ \\
\hline Bulbar Palsy & 4 & $10 \%$ \\
\hline Neck Muscle Weakness & 6 & $15 \%$ \\
\hline Sensory Disturbance & 13 & $32.5 \%$ \\
\hline Ophthalmoplegia & 3 & $7.5 \%$ \\
\hline Autonomic Dysfunction & 12 & $30 \%$ \\
\hline
\end{tabular}

Cerebrospinal fluid analysis was done for all the patients. Cerebrospinal fluid protein was increased in all the 40 patients ranging up to $60 \mathrm{mg}$. Cerebrospinal fluid cell count was up to 20 cells $/ \mathrm{mm}^{3}$.

Electrodiagnostic tests of the patients revealed that

1. Motor Nerve Conduction Velocity was decreased in all the 4 limbs varying from mild to severe degree.

2. Conduction block was present in 4 patients.

3. H- reflex could not be elicited in most of the patients.

4. Compound Muscle Action Potential was decreased in more than 30 patients.

The disease progressed in 38 patients up to 14 days. 35 patients worsened in the first week. 15 patients worsened after the first week. All patients had shown some improvement during hospital stay itself.

2 were discharged with some amount of residual disability. Among 40 patients in whom improvement had seen, recovery was rapid during the first week in 35 patients.

Cerebrospinal fluid analysis and electrodiagnostic studies were done only once during their hospital stay and follow up study could not be done. Magnetic resonance imaging was done in all patients which showed no evidence for cord compression or myelitis.

\section{Types of Guillain Barre Syndrome}

\begin{tabular}{|c|c|c|c|}
\hline Sl. No. & Type of GBS & No. of Patients & Percentage \\
\hline 1. & AIDP & 18 & $45 \%$ \\
\hline 2. & AMAN & 16 & $40 \%$ \\
\hline 3. & AMSAN & 12 & $30 \%$ \\
\hline 4. & MFS & 2 & $5 \%$ \\
\hline
\end{tabular}


38 of the patients received Intravenous Immunoglobulin (IVIG). 2 of them were given only Methyl Prednisolone. 5 patients went into respiratory failure despite being given IVIG and had to be given ventilator support.

Patients with AIDP and AMAN showed recovery from Grade 5 to Grade 2 on Modified Hughes Criteria. 2 patients with AMSAN variant had residual disability at the time of discharge. 12 patients had autonomic disturbance but recovered fully. There was no mortality among the study subjects during the period of study.

\begin{tabular}{|c|c|c|}
\hline Presentation & Number of Patients & Percentage \\
\hline Quadriparesis & 36 & $90 \%$ \\
\hline Paraplegia & 2 & $5 \%$ \\
\hline Respiratory Distress & 12 & $30 \%$ \\
\hline B/L Facial Palsy & 3 & $7.5 \%$ \\
\hline Bulbar Palsy & 4 & $10 \%$ \\
\hline Neck muscle weakness & 6 & $15 \%$ \\
\hline Sensory disturbance & 13 & $32.5 \%$ \\
\hline Ophthalmoplegia & 3 & $7.5 \%$ \\
\hline Autonomic Dysfunction & 12 & $30 \%$ \\
\hline Table 1. Various Types of Presentation of the Patients
\end{tabular}

\begin{tabular}{|c|c|c|c|}
\hline Sl. No. & Type of GBS & No. of Patients & Percentage \\
\hline 1. & AIDP & 18 & $45 \%$ \\
\hline 2. & AMAN & 16 & $40 \%$ \\
\hline 3. & AMSAN & 12 & $30 \%$ \\
\hline 4. & MFS & 2 & $5 \%$ \\
\hline \multicolumn{4}{|c|}{ Table 2. Classification of Patients according to Various } \\
Types of Guillain Barre Syndrome \\
\hline
\end{tabular}

\section{DISCUSSION}

40 patients were included in our study. The incidence of Guillain-Barré Syndrome was around 1.5\% in total hospital admissions in Department of General medicine. In a study done by McGrogan et al, ${ }^{2}$ where incidence was about 1.1\% $1.8 \%$.

$27.5 \%$ (11) of patients were below 30 years, $62.5 \%$ (25) of patients were between $30-60$ years and $10 \%$ (4) of patients were above the age of 60 . The age range of our consecutive patients has been 16 years to 68 years, with attack rates highest in persons less than 50 years of age.

Sex prevalence in our study was $57.5 \%$ (23) for men and $42.5 \%$ (17) for women.

Seasonal variation was observed in our study. This observation is supported by reports from India and China.

Those patients with coexisting illness like diabetes mellitus, systemic hypertension, ischemic heart disease and pulmonary tuberculosis were above the age of 40 and they had delayed recovery.

Approximately two thirds of patients reported a history of an antecedent event. According to the study by Rees et al, 3 1995 and Hughes RA et al, 4 preceding diarrhoeal illness, especially Campylobacter jejuni infection was documented in cases of acute motor axonal neuropathy.

$30 \%$ (12) of patients developed respiratory muscle weakness in some form. Diaphragmatic movement was assessed by Litten's phenomenon. Diaphragmatic weakness was increased during the second week and began to recover after the third week.

In patients with respiratory distress, need for ventilatory support was assessed by respiratory rate, single breath count, chest expansion, oxygen saturation and appearance of central cyanosis. In a study by Sharshar et al, 5 2003, short disease duration, inability to lift the head, and a vital capacity of less than $60 \%$ predicted the need for mechanical ventilation in $85 \%$ of patients. In our study, $12.5 \%$ (5) of our patients were put on ventilator of whom 4 had autonomic dysfunction.

Autonomic dysfunction was observed in 30\% (12) of patients. Orthostatic hypotension was detected in 8 patients; Abnormal sweating either increased or decreased sweating was looked for in the trunk and limbs. Arrhythmias were found in 5 patients. Benign arrhythmias like ventricular and atrial ectopics, and nonspecific ST-T changes, sinus tachycardia persisted for less than a week. Right heart failure was also observed in one patient.

In a study by Zochodne et al in 1994, 6 autonomic dysfunction was observed in $65 \%$ of patients and in another study by Winer and Hughes in 1998, 7 cardiac arrhythmias due to autonomic dysfunction was the leading cause of death, which contributed by 7 percent. Most of the patients with respiratory failure were found to have autonomic dysfunction and recovery was delayed. Mortality was increased in patients who have combined respiratory failure on ventilatory support and autonomic dysfunction, especially orthostatic hypotension and ventricular arrhythmias.

Bladder disturbance was one of the clinical presentations in 4 patients. Ultrasound examination of the abdomen was done in these patients and Benign Prostatic Hypertrophy (BPH) was ruled out. 13 patients had sensory disturbance in the form of impaired position and vibration sense. 12 patients were found to have sensory involvement on electrodiagnostic studies.

Around 95\% (38) patients received IVIG (Intravenous Immunoglobulin) as their treatment and showed good recovery. This is in accordance with the study done by Hughes RA et al., which showed that IVIG and Plasmapheresis show marked efficacy in the treatment of patients with GBS.

Most of the studies do not recommend the use of steroids. Yet many centres use high dose oral prednisolone or methylprednisolone. There was no significant difference in the outcome of patients treated with or without steroids, similar to the word literature. A randomized trial of oral prednisolone therapy by Guillain-Barré Syndrome steroid trial group in 1993, showed no benefit. Those patients above the age of 60 without any medical illness also, showed delayed recovery.

Prognosis in patients with Guillain-Barré Syndrome varied linearly with severity of demyelination or axonal degeneration detected by electrodiagnostic studies. Recovery was delayed in patients with conduction block when compared to patients with delayed motor nerve conduction velocity alone. Recovery was earlier and favourable in patients with absent H-reflex and $\mathrm{F}$ response and delayed motor conduction than in patients with conduction block.

A distal CMAP amplitude of less than $20 \%$ of the lower limits of normal was associated with poor outcome in the North American Guillain-Barré syndrome study group. Patients with high protein content in cerebrospinal fluid indicating demyelination of nerve roots showed delayed recovery. In a study by Ropper and Marmarou, ${ }^{8}$ the increase in cerebrospinal fluid protein had no clinical or prognostic significance. 


\section{Jemds.com}

In our study, patients with involvement of sensory as well as motor systems on the electrodiagnostic tests i.e., patients with the AMSAN variant showed delayed recovery and residual disability compared to the AMAN and AIDP variants where there was spontaneous recovery. This is in accordance with several studies performed on the electrodiagnostic types of GBS.

\section{CONCLUSION}

We can conclude from our study that Guillain Barre Syndrome is a treatable neurological condition with varying patterns of recovery.

Intravenous Immunoglobulin forms the mainstay of pharmacological treatment with recovery being shown in invariably all the patients who have received IVIG.

\section{REFERENCES}

[1] Ropper A, Samuels MA, Klein JP. Adams and Victor's Principles of neurology. $10^{\text {th }}$ edn. McGraw-Hll Education 2014.

[2] McGrogan A, Madle GC, Seaman HE, et al. The epidemiology of Guillain-Barré syndrome worldwide. A systematic literature review. Neuroepidemiology 2009;32(2):150-63.

\section{Original Research Article}

[3] Rees JH, Vaughan RW, Kandeatis E, et al. HLA class II alleles in GBS and Millar Fisher Syndrome and their association with preceding Campylobacter jejuni infection. J Neuroimmunol 1995;62(1):53-7.

[4] Sharshar T, Chevret S, Bourdain F, et al. Early predictors of mechanical ventilation in Guillain-Barré syndrome. Crit Care Med 2003;31(1):278-83.

[5] Hughes RA, Cornblath DR. Guillain-Barré syndrome. Lancet 2005;366(9497):1653-66.

[6] Zochodne DW. Autonomic involvement in GuillainBarré syndrome: a review. Muscle Nerve 1994;17(10):1145-55.

[7] Winer JB, Hughes RA, Anderson MJ, et al. A prospective study of acute idiopathic neuropathy. II. Antecedent events. J Neurol Neurosurg Psychiatry 1988;51(5):613-8.

[8] Ropper AH, Marmarou A. Mechanism of Pseudotumor in Guillain-Barré syndrome. Arch Neurol 1984;41(3):259-61. 